University of Michigan Law School

University of Michigan Law School Scholarship Repository

1907

\title{
Humanistic, and Particularly Classical, Studies as a Preparation for the Law
}

\author{
Harry B. Hutchins \\ University of Michigan Law School
}

Available at: https://repository.law.umich.edu/articles/1316

Follow this and additional works at: https://repository.law.umich.edu/articles

Part of the Legal Education Commons

\section{Recommended Citation}

Hutchins, Harry B. "Humanistic, and Particularly Classical, Studies as a Preparation for the Law." Sch. Rev. 15 (1907): 423-9.

This Article is brought to you for free and open access by the Faculty Scholarship at University of Michigan Law School Scholarship Repository. It has been accepted for inclusion in Articles by an authorized administrator of University of Michigan Law School Scholarship Repository. For more information, please contact mlaw.repository@umich.edu. 
III. HUMANISTIC, AND PARTICULARLY CLASSICAL, STUDIES AS A PREPARATION FOR THE LAW

\author{
DEAN H. B. HUTCHINS \\ Department of Law, University of Michigan
}

Aside from the elementary branches, no particular subject is absolutely essential as a basis for the study and practice of the law. In this respect the law occupies a place somewhat different from that of the other learned professions. The student and practitioner of medicine must of necessity get a substantial scientific foundation for his professional work. This for him is an absolutely essential prerequisite. For the professional courses in engineering a special and definite scientific preparation must be made; without it nothing but the most ordinary work in engineering can be accomplished. And it is probable that for theology, work along certain well-defined lines is desirable, if not essential. But it by no means follows that, because success in the study of the law or in the practice of it does not depend upon the mastery of particular subjects, a thorough preparation therefor is noc necessary. The contrary is most emphatically true, particularly at the present time. The law is a practical subject, most intimately connected with the private interests of the citizen, and with questions affecting his public rights and obligations; but it is at the same time a science, the mastery of which requires a mental equipment above the ordinary. No one can hope for much success as a student of it without adequate preliminary training, or in its application as an art, without being prepared for the keenest kind of intellectual competition.

Upon the very threshold of his work the law student discovers that his success is to depend very largely upon his equipment-not upon his having mastered any particular subject, but upon his having made himself master of his own mental processes to such an extent that he can do independent and original thinking. The fundamental principles of the different departments of the law must be mastered, and that their full significance may be appreciated, their historical development througin the successive decisions of the courts, must be traced. But he 
soon discovers that his task embraces more than the memorizing of principles, and the study of their origin and growth. His eyes are soon opened to the fact that the serious business of the law student consists in the application of general principles to the solution of problems involving new conditions and varying statements of fact. And then, too, he discovers directly thal, although the body of the settled law is large, there are continually arising questions upon which the law is unsettled, and whose solution requires the harmonizing, if possible, of conflicting decisions, or, where this is not possible, the determination as to the weight of reason and authority. He soon discovers that for every step taken and for every conclusion reached a logical and forceful reason must be assigned. It is needless for me to suggest that work of this nature, if successfully accomplished, calls for analytical power and constructive ability; it demands the informed and trained judgment of an educated man. While occasionally one having a natural aptitude for the law may be able, even with limited preparation, to master its principles and the art of its application, and to push to the front with apparent ease, the fact remains that, as a rule, the appreciative and successful study of jurisprudence demands preliminary training of a high order and of the thorough and rigorous kind.

And if such training is necessary for the student, it is certainly doubly so for the practitioner. He must be master, not only of legal principles, but also of the art of applying them to the actual affairs of life. The successful lawyer must not only have in mind and ready for immediate use the essential and fundamental doctrines of the law, but he must have his faculties so disciplined and under control that he is always prepared for emergencies. Men with ordinary equipment can do only ordinary things and fill the ordinary places, but the men who through ability and training are equal to the unexpected are bound to gc to the front. More perhaps than the man in any other profession does the lawyer need a large range of general information. His work is so varied, and touches life at so many different points and frequently in so unexpected a way, that he will constantly find himself embarrassed and handicapped without the intel- 
lectual masterfulness that comes from thorough and vigorous preliminary study. Unless his attention is especially challenged to the fact, the layman rarely appreciates the extent and variety of learning, aside from the strictly professional, that the lawyer must from time to time summon to his aid in the course of a varied career at the bar. If he has been liberally and thoroughly trained, the knowledge necessary for the emergency may be his: but if it is not his, he has what is quite as useful-the ability to acquire at short notice and under pressure the necessary special information.

The notion that I seek to impress, that large success at the bar demands great versatility and thorough general training, may perhaps be made more apparent by illustration. The litigation in hand may require the examination, by the lawyer in charge, of learned experts in some particular field of science-in electricity for example. In order to develop his case through the examination of his own experts, and to detect error and expose fallacies in the testimony of the experts of his adversary, it is absolutely essential that he have a working knowledge of the specialty. Moreover, in the argument of the case he must become in a sense the instructor of the court and of the jury, if there be one; for he must make plain to them the full significance of the scientific testimony adduced and its bearing upon the controversy that they are to decide. The full extent of the task will be appreciated when it is remembered that in many such cases, perhaps in most of them, both court and jury are ignorant of the ordinary and fundamental principles of the science involved, and must depend for their enlightenment entirely upon the skill of the attorneys in the development of the case through the testimony and its presentation in the argument. The case may be one involving the question of mental capacity, either to do a particular act, or to appreciate the moral and legal consequences of a particular act. A controversy of this kind plunges the lawyer at once into the uncertain domain of the alienist, and, in order that he may do his full duty to his client or the public, a working knowledge of the various forms of insanity is an absolute necessity. The extent to which a preparation in this regard 
at times becomes necessary, and the uses to which such preparation may be put, are well illustrated in the trial in New York: that is just now attracting so much public attention. Another striking illustration of the uses to which knowledge that apparently has little or no bearing upon the practice of the law may be put in a legal proceeding, is to be found in the recent insurance investigation by the Armstrong Committee in the city of New York. The remarkably brilliant work of Mr. Hughes in connection with that investigation has placed him in the front rank of American lawyers. His attitude upon public questions, and the belief of the people that he has the strength and the courage to accomplish the reforms that he advocates, together with his reputation as an honest and brilliant lawyer, have opened up for him a career outside of his profession; but it is simply to his work as a lawyer before the Armstrong Committee that I would direct attention. The secret of his achievement there was his preparedness, and the secret of his preparedness lay in the fact that, while securing a thorough preliminary training, he became a profound mathematician. The mathematics of insurance and the intricacies of insurance methods were to him an open book. His investigations, therefore, were thoroughly and rapidly made, and his conclusions fortified by a knowledge of details that to the uninitiated was simply marvelous. $\mathrm{He}$ was able to meet the insurance expert upon his own ground and to confound him by practical demonstrations of his wrong-doing.

But further illustration is probably unnecessary. It must be apparent, I think, that the lawyer, if he is to win a place in the profession, must be able to summon to his aid such special knowledge as may be necessary to meet the exigencies of his practice as they may arise. It cannot be expected, of course, that any considerable part of this will be secured through preliminary study. Occasionally such study may furnish it. But preparatory training, if of the proper sort, will furnish what, in a large way, is vastly more important than special knowledge, namely, the ability to assimilate and put to practical use, as the occasion demands, the results of the work of other men.

The foregoing, by way of introduction, leads naturally, I 
think, to the suggestion that I desire to emphasize, namely, that preparation for the law should be made by the study of such subjects as will train a man to acquire easily and rapidly, and to think logically and independently. And, in my judgment, the subjects the study of which tends to the development of these qualities are those which require of the student strenuous, painstaking, and persistent effort for their mastery. If I could regulate the preparation of law students, I would eliminate from the course all predigested and specially prepared foods, and I would give the young man something that would demand earnest effort on his part to assimilate. While I believe in and advocate $a$ thorough college course as a preparation for the study of law, and while I hope that the time is not far distant when such a course, or its equivalent, may be made a prerequisite for legal study, I am frank to say that the young man who has a thorough, old-fashioned classical and mathematical preparation for college is, in my judgment, much better fitted for the study of law than is the man who during four years in college has dissipated his energy and weakened his power to think clearly and logically by desultory and pointless work in "snap" courses that require little or no effort on his part. But I wish it understood that in making this statement, I do not intend a criticism of the elective system as such, for I believe in it, but I believe also that it should always be so supervised and regulated that disciplinary subjects predominate during at least the first half of the course. Under such a plan the student comes to the specialized work of the last two years with a quickened and strengthened mind and an informed judgment.

And it is because the preparatory study of the law student should be of the strenuous kind that the ancient classics may well take a prominent place in the preliminary course. There can be no question, I think, as to their disciplinary value. It is quite impossible for one to master the elements of Latin or Greek, and to attain a reading familiarity with either of those languages, without a painstaking and continuous mental effort. There must be a persistent training of the memory and a constant exercise of the judgment. For the prospective lawyer there can be no 
better discipline than that which comes from the discriminating effort involved in careful translation. The lawyer's professional life must be largely devoted to the interpretation of the law, and to the preparation and interpretation of legal instruments; and the greater his skill in the use of language and in discovering shades of meaning, the greater his effectiveness. But, putting all this aside and conceding, for the moment, that the study of the ancient classics is without practical value, and that whatever we learn of them is soon forgotten, we still cannot escape the fact that the mental power and effectiveness that are the results of that study remain with the man and become a part, and a very large part, of his equipment for the activities of life.

But while I would urge the study of the classics as a part of the preparatory law course largely for their disciplinary value, I would also urge that study on account of the facility that it tends to give in the use of English. As to this there can be no question. There is in regard to this practically no difference of opinion among educators. The study of English can best be made through the Latin language. And that the lawyer needs to know English goes without saying. The most effective, men at the bar are those who, with good legal attainments, are able to write and speak simple, clear, concise, and forceful English. I do not mean by this that success at the bar at the present time depends upon oratory, as popularly understood, or upon the arts of the orator, for this is not the fact, but it does depend very largely upon the ability of the practitioner to clothe his ideas in a few words so arranged as to challenge at once the attention. A distinguished English judge has said that a case clearly stated is half won, and there is certainly truth in the suggestion. One of the difficult tasks of the law teacher is to get from the student a clear, concise, and definite statement of the facts of the case that is to form the basis of discussion, and in this part of the work the noticeable superiority of the classically trained student is apparent.

It must be conceded, of course, that the study of Latin is of practical value to the law student by reason of the fact that Latin terms are very generally used in the law. This, however, I 
regard as a matter of minor importance, for through the aid of the dictionary the meaning of such terms is easily ascertained. However, a student who has a reading knowledge of the language is able to appreciate the terms at once and without the necessity of special study.

It is hardly necessary to suggest that, if one is to devote himself to the scholarly side of the law, he should be classically trained, and that his knowledge of Latin and Greek should be supplemented by at least a reading knowledge of French and German. The field of the jurist is a broad one, and the ease and thoroughness of his investigations depend very largely upon his ability to reach and master the sources of information through the texts of the originals.

The case that we seek to establish would not be complete without the suggestion that the culture value of humanistic study should not be overlooked in the consideration of what should be the training of the prospective lawyer. We are too apt to forget. in these intensely practical times, that the professional man should be first of all the well-educated gentleman. The lawyer should be more than a lawyer, the physician more than a physician, the engineer more than an engineer. Each should have an educational basis that fits him for something outside of, and beyond, his profession. I would not for a moment clair: that a man cannot be well educated without a knowledge of the ancient classics, for such is not the fact, but that humanistic study stimulates the mind to seek what is best in literature and art, and furnishes a source of culture and entertainment that broadens the man, and enables him to have an appreciative sense of the value of things outside of the narrow limits of his specialty, cannot admit of doubt. 